\title{
ПЕРСПЕКТИВНЫЕ МЕТОДЫ НЕИНВАЗИВНОЙ МЕДИЦИНСКОЙ ДИАГНОСТИКИ С ИСПОЛЬЗОВАНИЕМ НАНОМАТЕРИАЛОВ: СПЕКТРОСКОПИЯ ГИГАНТСКОГО КОМБИНАЦИОННОГО РАССЕЯНИЯ В ИССЛЕДОВАНИИ КЛЕТОК, КЛЕТОЧНЫХ ОРГАНЕЛЛ, МАРКЕРОВ НЕЙРОМЕДИАТОРНОГО ОБМЕНА
}

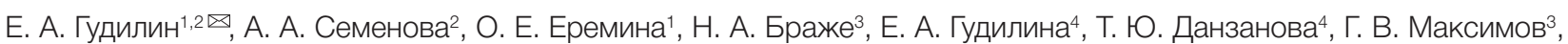
И. А. Веселова ${ }^{1}$

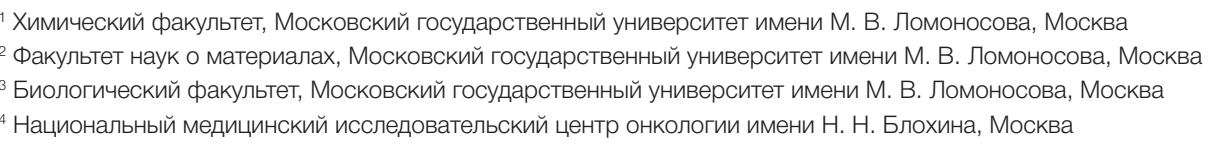

Использование достижений наномедицины и материаловедения в диагностике заболеваний является перспективным направлением научных исследований. Спектроскопия гигантского комбинационного рассеяния (ГКР) инновационный метод анализа, связанный с применением наноматериалов на основе благородных металлов для неинвазивного исследования клеток, клеточных органелл, белковых молекул. В работе обобщены литературные данные по методам ранней клинической диагностики ряда нейродегенеративных и нейроэндокринных заболеваний. Обсуждены особенности, достоинства и ограничения различных методов диагностики по низкомолекулярным и высокомолекулярным маркерам указанных заболеваний. Продемонстрированы перспективы применения оптических методов для экспресс-диагностики нарушений нейромедиаторного обмена. Особое внимание уделено новым подходам при создании универсальных оптических индикаторных систем, расширяющих аналитические возможности спектроскопии ГКР, обладающей уникально высокой чувствительностью, селективностью и воспроизводимостью результатов анализа при определении целевых аналитов в биологических матрицах сложного состава.

Ключевые слова: медицинская диагностика, наноматериалы, наночастицы благородных металлов, гигантское комбинационное рассеяние, митохондрии, эритроциты, маркеры нейромедиаторного обмена, наномедицина

Финансирование: работа поддержана Российским научным фондом (грант 14-13-00871).

Благодарности: авторы благодарны академику В. П. Чехонину за возможность творческого сотрудничества и Э. Никельшпарг за помощь В подготовке иллюстраций к обзору, а также профессору Г. Т. Синюковой за плодотворное обсуждение результатов ультразвуковой диагностики с использованием контрастных агентов.

$\square$ Для корреспонденции: Евгений Алексеевич Гудилин

Ленинские горы, д. 1, стр. 3, г. Москва, 119992; goodilin@yandex.ru

Статья получена: 20.07.2018 Статья принята к печати: 19.08.2018

DOI: $10.24075 /$ vrgmu.2018.077

\section{PROMISING METHODS FOR NONINVASIVE MEDICAL DIAGNOSIS BASED ON THE USE OF NANOPARTICLES: SURFACE-ENHANCED RAMAN SPECTROSCOPY IN THE STUDY OF CELLS, CELL ORGANELLES AND NEUROTRANSMITTER METABOLISM MARKERS}

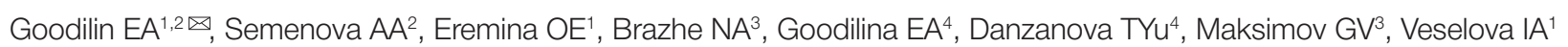

' Faculty of Chemistry, Lomonosov Moscow State University, Moscow

Faculty of Materials Science, Lomonosov Moscow State University, Moscow

${ }^{3}$ Faculty of Biology, Lomonosov Moscow State University, Moscow

${ }^{4}$ Blokhin Russian Cancer Research Center, Moscow

Application of advances in nanomedicine and materials science to medical diagnostics is a promising area of research. Surface-enhanced Raman spectroscopy (SERS) is an innovative analytical method that exploits noble metal nanoparticles to noninvasively study cells, cell organelles and protein molecules. Below, we summarize the literature on the methods for early clinical diagnosis of some neurodegenerative and neuroendocrine diseases. We discuss the specifics, advantages and limitations of different diagnostic techniques based on the use of low- and high molecular weight biomarkers. We talk about the prospects of optical methods for rapid diagnosis of neurotransmitter metabolism disorders. Special attention is paid to new approaches to devising optical systems that expand the analytical potential of SERS, the tool that demonstrates remarkable sensitivity, selectivity and reproducibility of the results in determining target analytes in complex biological matrices.

Keywords: medical diagnostics, nanomaterials, noble metal nanoparticles, surface-enhanced Raman spectroscopy, mitochondria, erythrocytes, neurotransmitter markers, nanomedicine

Funding: this work was supported by the Russian Science Foundation (Grant 14-13-00871).

Acknowledgments: the authors wish to thank Professor Chekhonin VP, who graciously agreed to collaborate on this project, Nickelsparg E. for her assistance in preparing the figures for the manuscript, and Professor Sinukova GT for the fruitful discussion of contrast-enhanced ultrasound diagnostics.

$\triangle$ Correspondence should be addressed: Eugene A. Goodilin

Leninskie gory 1, bl. 3, Moscow, 119992; goodilin@yandex.ru

Received: 20.07.2018 Accepted: 19.08.2018

DOI: $10.24075 /$ brsmu.2018.077 
Развитие наномедицины и материаловедения в интересах медицинской диагностики является перспективным направлением научных исследований на стыке химии, физики, биологии на протяжении последних 10-15 лет [1-3]. Обычно в качестве наиболее значимых перспектив дальнейшего развития данной области рассматривают направленную доставку лекарств, тераностику, терапевтическое воздействие наночастиц, а также исследование «диагностических» наноматериалов, связанных, в частности, с разработкой контрастирующих агентов для сцинтиграфии, КТ, МРТ и УЗИ (рис. 1), уже в ряде случаев вышедших на рынок и ставших стандартом проведения диагностических исследований; важнейшим шагом является создание новых поколений сенсорных систем [1, 2, 4-11].

В то же время среди важнейших интенсивно развивающихся методов неинвазивной биомедицинской диагностики сейчас однозначно выделяют спектроскопию гигантского комбинационного рассеяния (ГKР, или SERS от англ. surface-enhanced raman scattering) - рекордный по чувствительности оптический метод анализа объектов природы и уникальный подход для практического экспресс-мониторинга [12-15]. В силу фундаментальных физических принципов, на которых базируется, он напрямую нуждается в разработке новых наноматериалов с контролируемым комплексом свойств на основе наноструктур серебра и золота; последние демонстрируют не только высокий контроль над плазмонным резонансом и распределением локальных электромагнитных полей при внешнем возбуждении, но и достаточно высокую химическую и биологическую инертность (рис. 2). Приоритетными областями применения ГКР являются неразрушающий анализ биологических объектов, клеток и клеточных фрагментов [16-22], включая эритроциты [16, 17, 23-25], бактерии [26-28], вирусы [29, 30], стволовые клетки [31, 32], клетки тканей человека [33], в том числе раковые [34-37]; контроль лекарственных препаратов, пищевых продуктов [38, 39]; обнаружение и определение белков, пептидов, ДНК [9, 15, 19-21], низкомолекулярных биомаркеров заболеваний, отравляющих веществ [9-11, 36, 40-42]. Большинство проводимых в последнее время работ в области ГКР направлено на поиск практического внедрения метода, что свидетельствует о его высоком потенциале в биомедицинской диагностике.

Спектроскопия ГКР активно развивается с 1974 г. [43] и лишь с 2010-2012 гг. наметилась отчетливая тенденция ее использования в неинвазивном анализе живых клеток и клеточных органелл в связи с разработкой новых наноматериалов и инструментальных подходов [9, 13, 16-20]. В частности, спектроскопия ГКР активно сочетается с in vivo визуализацией [44], микрожидкостными устройствами [45], позволяющими существенно повысить потенциал ее применения. Использование спектроскопии ГКР обычно связывают с ее чрезвычайно высокой чувствительностью, что действительно важно для обнаружения и определения аналитов на уровне примесей, вплоть до детектирования отдельных молекул, однако в настоящее время от этого метода ожидают также успехов в реализации мультиплексного анализа в многокомпонентных матрицах реальных объектов. Потенциал для подобного развития
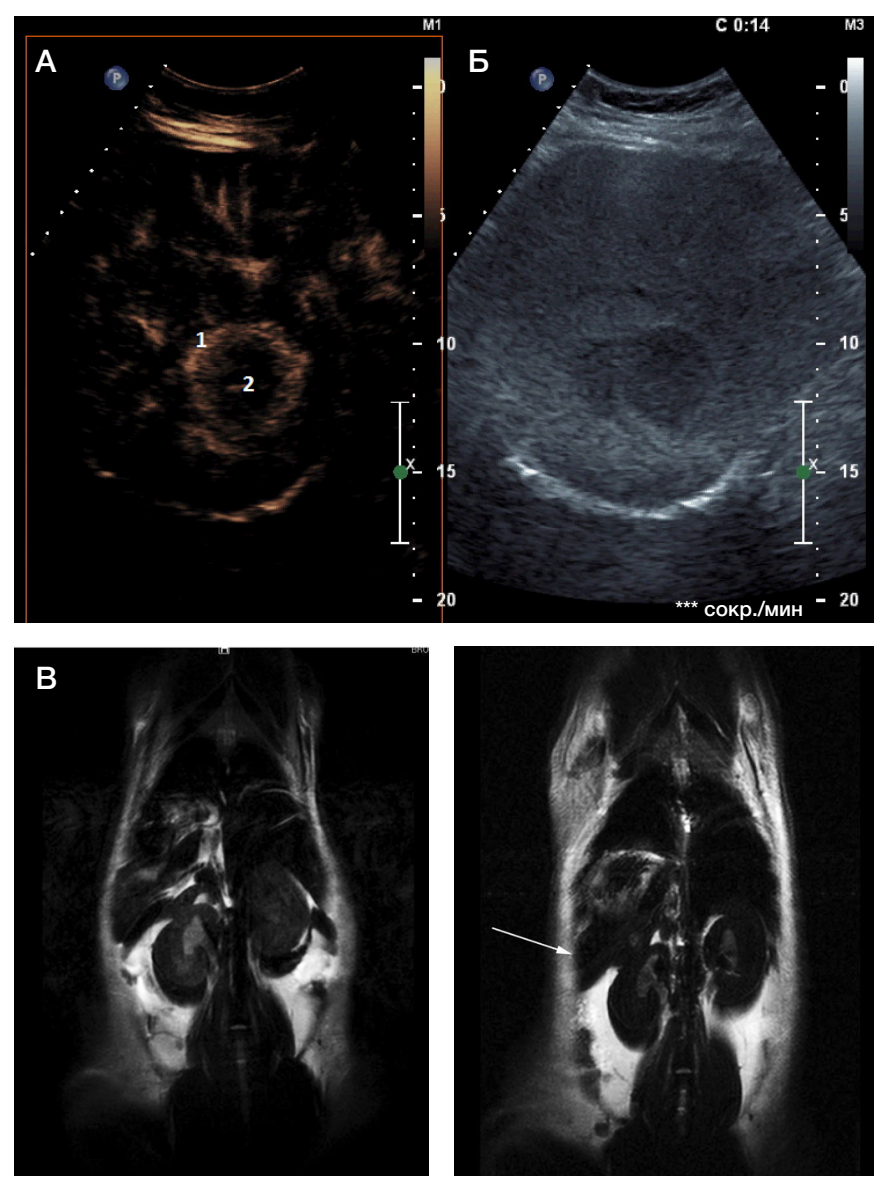

Рис. 1. Использование контрастных препаратов в медицинской диагностике (фотографии авторов). А, Б. Узи печени с контрастным усилением. Визуализируется метастатический очаг: A - артериальная фаза контрастирования (14 с после внутривенного введения контрастного препарата SоnоVие), 1 - периферическая контрастируемая зона; 2 - неконтрастируемая центральная зона; Б - серошкальный В-режим. В. Контрастирование селезенки лабораторной крысы на снимке МРТ магнитными наночастицами оксида железа с оболочкой, содержащей полиэтиленгликоль (ПЭГ) 
у метода, несомненно, существует, поскольку ГКРспектр обусловлен молекулярным строением вещества, что позволяет не только идентифицировать аналиты в сложных смесях по молекулярным «отпечаткам пальцев», но и определять конформации молекул.

Высокая чувствительность метода ГКР при решении таких комплексных аналитических задач, как обнаружение и идентификация веществ в матрицах сложного состава на уровне ультранизких (от нМ до фМ) концентраций, далеко не всегда сочетается с возможностью количественного определения аналитов. Спектроскопия ГКР относится к локальным методам анализа, в том числе потому, что усиление сигнала комбинационного рассеяния происходит на расстояниях не более 10-15 нм от наноструктурированной поверхности и существенно зависит от ее структуры и состояния, размера, анизотропии, взаимного расположения наночастиц, особенностей сорбции аналитов на наночастицах, а также формирования агрегатных структур [9]. В силу этого функциональные свойства разрабатываемого материала определяются широким набором его морфологических и микроструктурных характеристик, а также физикохимических свойств.

Для решения проблемы количественного анализа, повышения воспроизводимости, чувствительности и селективности метода спектроскопии ГКР развивают различные его модификации, адаптированные под конкретные задачи. Важным аспектом стало изучение так называемых «горячих точек» (hot spots) - областей с высокоинтенсивным локальным электромагнитным полем, возникающим в нанометровых зазорах между наночастицами [9], что играет существенную роль в эффекте усиления ГКР, поскольку предположительно именно В этих областях возможна регистрация спектральных сигналов с коэффиициентами усиления (КУ) более $10^{7}-10^{8}$ раз.

Существующие в настоящее время подходы к химическому синтезу позволяют получать с достаточно высоким выходом наночастицы серебра (НЧС) различных размеров и форм (сферы, тетраэдры, декаэдры, треугольные и гексагональные пластинки, диски, стержни, нити, частицы более сложных форм) [9, 46-51]. К физическим методам получения НЧС относят лазерную абляцию, термическое испарение, синтез в дуговом разряде, электронное испарение, ионное распыление, ионную имплантацию, методы с использованием различных излучений; определенный интерес представляют также методы получения наночастиц (НЧ) с использованием веществ природного происхождения [52-55]. Для создания планарных структур традиционны литографические, электрохимические подходы, осаждение из паровой фазы, химические методы осаждения, формирование пленок по методу Ленгмюра-Блоджетт, с использованием мицелл сополимеров, привитие предварительно полученных наночастиц к модифицированной амино- или тиольными группами поверхности микросфер, аэрозольные и физические методы напыления Н4 на различные подложки, включая целлюлозные носители, поверхности, модифицированные с использованием реплик [9, 11, 13, 16, 17, 25]. Перечисленные тенденции и предпосылки создания надежных ГКР-активных материалов, сенсорных устройств и методик анализа с использованием новых аналитических систем обусловливают прекрасные перспективы практического применения метода в области биомедицинской диагностики.

\section{Неинвазивная диагностика биологических объектов}

В настоящее время большой интерес вызывает применение спектроскопии ГКР для обнаружения следовых количеств биологически активных молекул в физиологических жидкостях (крови, слюне, цереброспинальной жидкости) с целью ранней клинической диагностики заболеваний. Для обнаружения некоторых физиологически активных молекул в биологических образцах спектроскопия ГКР нашла применение в сочетании с иммунохимическим методом, основанным на специфическом связывании антигена с комплиментарным антителом [56]; использование меток комбинационного рассеяния (КР-меток) в сочетании с применением композитных материалов на основе микрочастиц (микросфер) и металлических наночастиц открывает возможности проведения «управляемого» иммуноанализа для высокочувствительного обнаружения биомолекул [56-58]. Важную роль играет также разработка биосенсоров с возможностью количественного определения аналитов путем химической модификации поверхности плазмонных частиц, чаще всего - монослоем тиола с необходимыми функциональными группами, что используется для последующей селективной сорбции аналитов и обеспечения предконцентрирования [59]. Такой подход позволяет, например, проводить анализ глюкозы в реальном времени в диапазоне до 25 мМ, что близко к ее типичному содержанию в ряде физиологических жидкостей, в том числе в присутствии модельных белков плазмы (например, бычьего сывороточного альбумина) и при длительном (до трех дней) контакте сенсора с электролитами в «физиологических» концентрациях. При подкожной имплантации лабораторным животным ГКР-сенсоров данного типа устройства демонстрируют достаточно высокую правильность и воспроизводимость показателей в течение как минимум двух недель, что свидетельствует о больших перспективах использования ГКР-сенсоров для мониторинга состояния живых организмов in situ [59]. Предпочтительным при исследовании биологических объектов может быть использование наноструктурированных поверхностей, так как они обеспечивают воспроизводимый коэффициент усиления спектрального сигнала, а также позволяют интегрировать ГКР-активные материалы в лаборатории на чипе и микрожидкостные устройства. Независимо от того, какие наноструктуры применяют для исследования биообъектов, они должны удовлетворять следующим требованиям: быть нетоксичными для клеток, не изменяться химически и морфологически в биологических жидкостях и растворах, максимально стабильно усиливать сигнал КР, не влиять на клеточные процессы и конформацию тех клеточных молекул, с которыми они непосредственно контактируют.

Спектроскопия ГКР нашла применение в исследовании раковых клеток [60, 61]. С помощью ГКР-сенсоров можно измерять внутриклеточный редокс-потенциал. Предложена технология исследования окислительного стресса в клетках с помощью золотых наносфер с различными хинонами в качестве редокс-чувствительных молекул [62]. Она позволяет количественно оценивать редокс-потенциал клеток в диапазоне от -400 до +100 мВ более широком, чем с помощью существующих флуоресцентных зондов. Другим примером использования специфического ГКР-сенсора (высокоселективного гибридного наносенсора из наночастиц серебра, покрытых цитохромом с) для изучения окислительного стресса служит обнаружение супероксидного анион- 
радикала [63]. Предел обнаружения супероксидного анион-радикала равен 10 нМ. Метод основан на том, что при переносе электрона с супероксидного анион-радикала на цитохром с на спектре ГКР полоса, характерная для окисленного цитохрома с, смещается в положение, характерное для восстановленного цитохрома с.

Интересным подходом является использование наноструктур, модисицированных молекулами, не дающими яркий спектр ГКР, но способными высокоселективно связывать биологический объект, от которого регистрируют спектр ГКР. Примером может служить сенсор для высокочувствительного обнаружения бактерий в крови [64]. Золотые или композитные серебрянозолотые наноструктурированные поверхности покрывали ванкомицином, способным специфически связываться с грамположительными бактериями. Ванкомицин способствует десормации клеточной стенки бактерий что увеличивает агрегацию, приводя к усилению КР-сигнала. Перспективность таких подложек для создания мультифункциональных биочипов обусловлена возможностью замены слоя ванкомицина на другие гликопептиды с целью обнаружения широкого спектра микроорганизмов и вирусов. Проведен ряд исследований с использованием стеклянных микрокапилляров, покрытых наночастицами золота и вводимых внутрь клеток [65]. В зависимости от внутриклеточной локализации капилляра усиление сигнала шло от компонентов ядра или цитоплазмы, причем вид спектра зависел от функционального состояния клеток. Предложен метод, основанный на спектроскопии ГКР с использованием покрытий, декорированных золотыми наночастицами, для обнаружения вторичного мессенджера внутриклеточной молекулы, высвобождаемой в ответ на стимуляцию рецепторов и активацию первичных

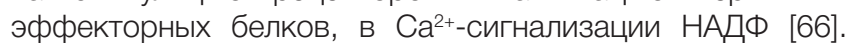
Разработаны наноматериалы на основе золота и новый методический подход для высокочувствительного определения изменений конформации нуклеиновых кислот и белков и визуализации клеток в условиях in vivo [9, 19, 20]. Предложены функционализированные золотые наночастицы для дискриминации различных типов лимфоцитов и выявления лейкемических клеток [67].

Одно из важных направлений ГКР-спектроскопии получение избирательного, высокоселективного усиления сигнала КР от конкретных внутриклеточных молекул, конформация и свойства которых отражают как их функционирование, так и работу всей клетки или конкретных органелл. К таким биомакромолекулам, удобным и перспективным в фундаментальных и прикладных исследованиях, относят гемсодержащие белки: гемоглобин (Гб) и цитохромы. Известно, что гемопорфирины и гемсодержащие белки обладают довольно интенсивным и высокоспецифическим комбинационным рассеянием [68], зависящим от редокс-состояния атома железа и конформации гема и его белкового микроокружения. Эта особенность позволяет исследовать цитохромы митохондрий в клетках и органах [9], гемоглобин в цельной крови, изолированных эритроцитах и эритроцитах в сосудах в условиях in vivo. При этом существует ряд ограничений традиционной спектроскопии КР в изучении гемопорфиринов: цитохромы в окисленном состоянии обладают низкоинтенсивным и поэтому недетектируемым KР, а КР-исследования эритроцитов позволяют получать КР-спектры только от цитоплазматического Гб (Гб составляющего основное количество Гб, но не от мембранносвязанного Гб (Гб $)$, конформация которого может изменяться специфическим образом при различных системных патологиях кровеносной системы, наследственных и эндокринологических заболеваниях (талассемии, гемоглобинопатии и др.) [69], при интоксикации, при функционировании организма человека в экстремальных условиях [70] — в этих случаях усиление сигнала КР происходит именно от Гб в непосредственной близости к наноструктурам серебра. Таким образом, применение ГКР-активных наноструктур незаменимо в исследованиях гемсодержащих белков и может служить основой для проведения неинвазивной медицинской экспресс-диагностики и скрининга.

Авторами предложен новый методический подход, а также разработаны и синтезированы наноструктурированные материалы с планарной архитектурой и нанокомпозиты $\mathrm{Ag} @ \mathrm{SiO}_{2}$, позволившие получить высоковоспроизводимое и селективное интенсивное усиление сигнала КР от цитохрома с дыхательной цепи (электронтранспортной цепи, ЭТЦ) интактных функционирующих митохондрий (рис. 2Г). В результате были исследованы изменения конформации и редокс-свойств цитохрома с в интактных функционирующих митохондриях при модуляции активности дыхательной цепи $[9,18]$. Кроме того, были показаны изменения редокс-состояния и конформации гема цитохрома $c$ при внесении протонофоров, вызывающих разобщение дыхания и синтеза АТФ, а также при блокировании АТФ-синтазы. Спектроскопия ГКР с планарными серебряными плазмонными структурами позволяет оценивать изменение относительного содержания восстановленного цитохрома $c$ в митохондриях и конформационную подвижность гема в цитохроме $c$ как в составе митохондрий, так и в изолированном состоянии (рис. 2Г). На интактных митохондриях было показано, что протоносрор FCCP, разобщающий синтез АТФ и транспорт электронов, и олигомицин, блокирующий АТФ-синтазу, разнонаправленно влияют на относительное содержание восстановленного цитохрома с и подвижность метиновых мостиков в геме [18], а мутантные формы цитохрома с с увеличенной жесткостью белкового микроокружения гема обладают меньшей конформационной подвижностью и функциональной активностью гема. Предполагается, что изменение конформации гема цитохрома с может быть использовано в митохондриях для варьирования скорости акцептирования электрона от комплекса III ЭТЦ и передачи электрона комплексу IV. Предложенный методический подход перспективен для дальнейшего изучения работы ЭТЦ интактных митохондрий. Для применения ГКР-активных наноструктур в биомедицинских целях необходима разработка методов анализа данных для интегрирования наноструктур в «лаборатории-на-чипе».

\section{Экспресс-диагностика нарушений нейромедиаторного обмена}

Нейромедиаторный обмен лежит в основе нервной медиации как периферической, так и центральной нервной системы [71]. Ключевыми маркерами нейромедиаторного обмена служат соединения группы катехоламинов (KA) дофамин (ДА), адреналин (АД), норадреналин (НА) и такие их метаболиты, как ванилилминдальная (ВМК), гомованилиновая (ГВК) и 5-гидроксииндолуксусная (5ГИУК) кислоты, метанефрин (МН) и норметанесрин (НМН). Метаболизм КА играет важную роль в регулировании как умственной, так и физической деятельности человека: 

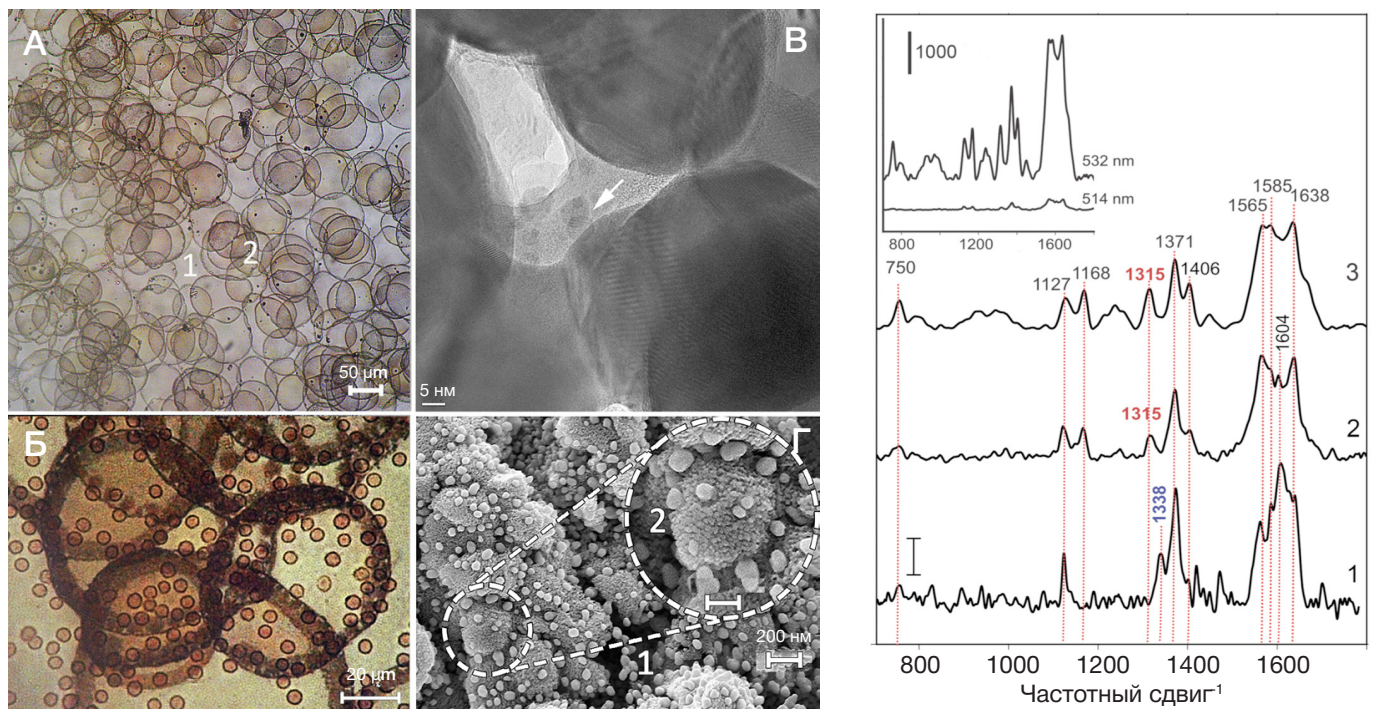

Рис. 2. Структура наноструктурированной серебряной подложки для ГКР-анализа. А. Оптическое изображение наноструктурированного покрытия с кольцевой структурой подложки. Б. Расположение живых эритроцитов на подложке при ГКР-анализе. В. Наноструктурированные элементы подложки (формирование наночастиц серебра в каналах покрытия, ПЭМ). Г. «Кунжутные зерна» на поверхности ГКР-покрытия (РЭМ). Д. Спектры ГКР эритроцитов (1) и митохондрий (2 и 3) на нанокомпозитных Ag@SiO 2 коллоидосомах при лазерном возбуждении 532 нм (1 и 3) и 514 нм (2). Для удобного восприятия спектры нормированы на суммарную интенсивность спектра. Числа над спектрами показывают положения максимумов основных пиков. На вкладке представлены ненормированные спектры ГКР митохондрий на коллоидосомах при лазерном возбуждении 514 и 532 нм

действуя через дофаминергические и адренергические рецепторы, КА участвуют в регуляции реакций организма на стресс, психомоторной активности, эмоциональных реакций, обучения, сна и памяти [72]. Поскольку КА задействованы в патогенезе многих болезней, они являются эффективными и широко применяемыми лекарственными препаратами [73]. Связанные с нарушениями нейромедиаторного обмена заболевания делят на две основные группы: нейродегенеративные, сопровождающиеся прогрессирующей гибелью нервных клеток и уменьшением содержания КА и их метаболитов в организме соответственно, и нейроэндокринные, характеризующиеся избыточным синтезом КА из-за органического поражения или генетической дефектности гипоталамуса. $\mathrm{K}$ основным нейродегенеративным заболеваниям относят болезни Альцгеймера (БА) и Паркинсона (БП), к нейроэндокринным катехоламинпродуцирующим опухолям - феохромоцитому, параганглиому, карциноидные опухоли и нейробластому.

Диагностика нейроэндокринных опухолей представляет собой значительную проблему, поскольку злокачественное новообразование часто диагностируют уже в ретроспективе, в период развития метастатической или рецидивирующей стадии. Как правило, более 90\% нейродегенеративных заболеваний в России не удается диагностировать, поскольку их симптомы расценивают как признаки возрастных изменений. Многие нейродегенеративные нарушения характеризуются схожими симптомами, что может отрицательно влиять на правильность диагноза по клиническим наблюдениям за больными [74]. К наиболее серьезным нейроэндокринным заболеваниям, в процессе развития которых повышается содержание KA в организме, относят феохромоцитому и параганглиому - доброкачественную и злокачественную катехоламинпродуцирующие опухоли. Они возникают из хромаффинных клеток симпатоадреналовой системы, которые в 90\% случаев локализованы в мозговом слое надпочечников [75]. Карциноидные опухоли составляют менее 1\% всех злокачественных опухолей и образуются из клеток диффузной нейроэндокринной системы, возникающей из клеток нервного гребешка в период эмбриогенеза и мигрирующих в различные органы [76]. Еще одна злокачественная опухоль, нейробластома, сопровождается образованием многочисленных метастазов. Большинство опухолей обнаруживается в забрюшинном пространстве, чаще всего в надпочечниках; реже встречаются в средостении и шее [77].

Катехоламины ДА и НА и их метаболиты могут выступать в качестве молекулярных маркеров при диагностике БП и БА: по снижению их содержания в биологических жидкостях можно судить о начале заболевания. В частности, показано, что с развитием симптоматики БП в моче понижается соотношение ДА и диоксифенилуксусной кислоты (ДОФУК) и уменьшается выброс ДА и диоксифенилаланина (ДОФА). Уже на ранней стадии паркинсонизма наблюдается ярко выраженный дефицит биохимических нейромедиаторов катехоламиновой природы (ДА, НА и серотонина) с одновременным развитием катаболизма ДА вследствие усиления процесса его окислительного дезаминирования в сравнении с нормой. Однако при начальных клинических проявлениях БП возрастает кругооборот ДА, что носит компенсаторный характер. По мере прогрессирования дегенеративного процесса выявляются отчетливое снижение уровня ДОФА и уменьшение соотношения ДА/ДОФУК как показателя нарушения нейромедиаторного обмена в результате снижения активности моноаминоксидазных процессов, что свидетельствует об истощении резервов для синтеза KA. Таким образом, КА являются перспективными биомаркерами нейродегенеративных заболеваний вследствие закономерного изменения их концентрации в ходе болезни и относительно простой молекулярной структуры.

Трудность определения KA В биологических жидкостях обусловлена тем, что у здорового человека их концентрации изначально очень низки (на уровне 1 нМ), а при различных патологических нарушениях они снижаются еще на порядок (БА и БП). При этом следует учитывать, что в крови КА быстро окисляются моноаминоксидазами тромбоцитов, в связи с чем определение маркеров 
нейромедиаторного обмена в организме должно происходить очень быстро (в течение 15-30 мин). По этой причине актуален поиск доступных селективных и чувствительных экспресс-методик определения КА и их метаболитов в биологических жидкостях.

В настоящее время для диагностики на ранних стадиях нейродегенеративных заболеваний применяют, главным образом, нейровизуализационные методы анализа: МРТ, КТ, позитронно-эмиссионную томографию (ПЭТ), однофотонную эмиссионную КТ (ОФЭКТ), протонную магнитно-резонансную спектроскопию (МРС), электроэнцефалографическое исследование (ЭЭГ) и др. $[10,11]$. В последнее время для диагностики БА и БП стали активно применять ПЭТ и ОФЭКТ. Однако доступность этих радионуклидных томографических методов в значительной степени определяется арсеналом доступных меченых соединений - радиофармпрепаратов (РФП), предварительно вводимых в организм человека. Как правило, в качестве радиоактивной метки в случае ПЭТ используют биологически важные короткоживущие $\left({ }^{18} \mathrm{~F}\right)$ и ультракороткоживущие $\left({ }^{11} \mathrm{C},{ }^{13} \mathrm{~N},{ }^{15} \mathrm{O}\right)$ позитронизлучающие радионуклиды [10]. Другой метод молекулярной визуализации, ОФЭКТ, позволяет оценивать функциональное состояние различных отделов головного мозга, что может иметь значение при диагностике нейродегенеративных заболеваний со схожей клинической картиной, но различающихся вовлечением отдельных участков мозга. Нейровизуализационные методы позволяют достаточно точно диагностировать различные нейродегенеративные и нейроэндокринные заболевания, в том числе на ранних стадиях. Однако прогнозирование заболеваний с использованием перечисленных методов невозможно. Кроме того, исследования такого рода не всегда доступны из-за отсутствия подходящего оборудования, высокой себестоимости исследования, а также медицинских показаний пациентов. При большой распространенности заболеваний инструментальная диагностика нередко доступна только жителям крупных городов. Следовательно, актуальны поиск и разработка новых подходов к мультиплексному чувствительному экспрессному $и$ не требующему дорогостоящего оборудования и высококвалисицированного персонала определению маркеров биохимических процессов, лежащих в основе патогенеза некоторых психоневрологических заболеваний и опухолевого роста.

Более простой и доступный подход $\mathrm{k}$ диагностике БА и БП заключается в иммунохимическом определении биохимических маркеров нейромедиаторного обмена. В качестве таких соединений в случае БА могут выступать некоторые высокомолекулярные соединения, прежде всего белки - $\beta$-амилоидный пептид, таупротеин, фосфорилированный тау-протеин. Для БП характерно накопление белка синуклеина, а у больных БА формируются сенильные бляшки - белковые клубки, содержащие много $\beta$-амилоидного пептида, методы определения которого разрабатываются в последние годы. Распределение $\beta$-амилоида в организме можно изучать как радиоизотопными инструментальными методами, так и с помощью иммунохимического анализа цереброспинальной жидкости [10, 11]. Однако существенным недостатком метода является сложная и длительная процедура пробоподготовки объекта исследования. Перспективным подходом к диагностике нейродегенеративных заболеваний является разработка иммунохимических тест-методов определения биомаркеров, однако ограничения иммунохимических методик связаны со сложностями как объекта анализа, так и структуры диагностических молекул. Кроме того, содержание белковых маркеров может варьироваться в зависимости от возраста и пола пациента [10], что нередко приводит к получению ложных результатов анализа. Белки могут служить биологическими маркерами и для диагностики нейроэндокринных заболеваний. Так, хромогранин А (CgA), присутствующий в хромаффинных гранулах нейроэндокринных клеток, используют для диагностики феохромоцитомы, параганглиомы, нейробластомы и карциноидных опухолей $[10,11]$, однако этот метод не позволяет достоверно установить, какое именно нейроэндокринное заболевание прогрессирует у пациента. Поэтому помимо обычно используемых биохимических показателей для диагностики нейробластомы рассматривают такие маркеры, как нейронспецифическая энолаза, ферритин, лактатдегидрогеназа, $\gamma$-глутамилтрансфераза [10, 11]. Очевидно, что становятся актуальными поиск и изучение биохимических маркеров небелковой природы, таких как KA и их метаболиты, а также разработка простых селективных и высокочувствительных методов их определения, обеспечивающих точный и достоверный результат на ранних стадиях заболеваний.

В процессе нейромедиаторного обмена происходят инактивация и метаболизм КА. КА метоксилируются в присутствии катехол-о-метилтрансферазы (КОМТ) с выделением метанифрина (МН) и норметанефрина $(\mathrm{HMH})$. Кроме того, КА окислительно дезаминируются в присутствии фермента моноаминооксидазы (МАО) с образованием ванилилминдальной (ВМК) и гомованилиновой (ГВК) кислот в качестве конечных продуктов [10, 11]. В связи с тем, что содержание КА и их метаболитов в норме и при патологии различно, их можно использовать в качестве диагностических маркеров как при проведении фундаментальных исследований, так и в клинической практике. Среди методов, применяемых для диагностики нейродегенеративных и нейроэндокринных заболеваний по содержанию КА и их метаболитов в моче и крови, наиболее широко используют хроматографические методы в сочетании с электрохимическим (ЭХ) или массспектрометрическим (МС) детектированием [11]. Несмотря на высокую селективность, чувствительность, доступность используемых электрохимических детекторов, они характеризуются плохой воспроизводимостью, чувствительностью к флуктуациям в скорости потока подвижной фазы, загрязнением электрода, повышенными требованиями к природе подвижной фазы. Для метода высокоэффективной жидкостной хроматографии с электрохимическим детектированием (ВЭЖХ-ЭХ) характерны высокие значения фонового шума по сравнению с полезным сигналом, не всегда достаточная чувствительность и низкая эффективность разделения компонентов. Метод ВЭЖХ-МС/МС характеризуется значительно большей чувствительностью определения KA и их метаболитов, однако является недостаточно экспрессным и имеет ограничения, связанные с элюированием определяемых соединений в мертвое время, значительными шумовыми помехами и сложностью разрешения пиков [11]. Несмотря на кажущуюся изученность проблемы и наличие большого набора методов, позволяющих определять содержание КА в плазме крови и моче, относительная длительность анализа, низкая воспроизводимость и плохое разрешение обусловливают многочисленные диагностические ошибки, 
приводящие к неэффективному лечению. В последнее время ведутся разработки различных электрохимических сенсоров для определения KA и их метаболитов [78]. Действие большинства из них основано на модификации индикаторных электродов предварительно синтезированными соединениями с определенной структурой, обеспечивающими селективное определение КА, например молекулярными отпечатками ДНК, полимерами, искусственными рецепторами, различными нанотрубками и наностержнями, модифицированными органическими молекулами - полиэтиленимином, циклодекстрином, комплексами металлов [79-81]. Методики определения KA и их метаболитов электрохимическими методами характеризуются в основном средней чувствительностью на уровне 0,01-1 мкМ. Кроме того, большинство электрохимических методов позволяет селективно определять только единичные биохимические маркеры, т. е. не обеспечивает мультиплексность анализа, что ограничивает возможность их применения в клинической диагностике.

Другой альтернативой рассмотренным выше методам служат спектроскопические методы, выгодно отличающиеся простотой, экспрессностью, невысокой стоимостью анализа, в ряде случаев более высокой чувствительностью, чем у электрохимических и хроматографических методов. Перспективна разработка флуоресцентных методов определения KA и их метаболитов в целях диагностики различных заболеваний. KA в присутствии фермента (например, пероксидазы) [82] окисляются пероксидом водорода, а продукт их окисления служит тушителем фотолюминесценции водорастворимого полимера поли(2,5-бис(3-сульфонатопропокси)-1,4-фенилэтинилена-1,4-поли(фениленэтинилена)). Чувствительность определения КА по этой методике невысока (около 0,1 мкМ), зато возможно определение нескольких КА с высокой групповой селективностью [83]. Известны методики с использованием наночастиц, например на основе $\mathrm{Fe}_{3} \mathrm{O}_{4}$. Их применяют как аналог пероксидазы из корней хрена. Подход основан на ингибировании KA реакции окисления реагента Amplex UltraRed (субстрата пероксидазы) в присутствии пероксида водорода и наночастиц $\mathrm{Fe}_{3} \mathrm{O}_{4}$, продукт которой интенсивно флуоресцирует при 587 нм при возбуждении при 567 нм. Как следствие, КА ковалентно связывается с поверхностью наночастиц оксида железа (III) и тушит флуоресценцию продукта окисления Amplex UltraRed. Несмотря на весьма высокую чувствительность (предел обнаружения составляет 3 нМ), эта методика тоже обладает лишь высокой групповой селективностью по отношению к KА и их метаболитам, но не позволяет осуществлять мультиплексный анализ [84]. К сожалению, чувствительность большинства подобных методов не позволяет определять наномолярные содержания катехоламинов, что ограничивает применимость разработанных сенсорных систем в анализе биообъектов $[10,11]$.

Недостатков, присущих существующим методам определения КА и их метаболитов, прежде всего связанных с низкой селективностью и экспрессностью анализа, в той или иной мере лишены методы, использующие спектроскопию КР. Сами по себе эти методики позволяют определять нейромедиаторы лишь на уровне концентраций 0,1-0,5 М [85], что, очевидно, не удовлетворяет требованиям, предъявляемым к анализу биологических жидкостей. Перспективным подходом является создание высокочувствительных и селективных оптических сенсорных систем на основе метода ГКР, основанного на усилении сигнала КР за счет эффекта плазмонного резонанса на наноструктурированной поверхности благородных металлов, как обсуждалось выше. Специфичность анализа достигается за счет регистрации ГКР-сигналов в области 1500-650 см-1, обладающих высокой информативностью для обнаружения индивидуальных соединений в смесях сложного состава. Как указывалось, ГКР-спектроскопия очень чувствительна к незначительным изменениям в структуре и ориентации молекул, поэтому, благодаря всем вышеперечисленным характеристикам в сочетании со слабым КР-сигналом воды, ГКР-спектроскопия представляется перспективным методом для анализа сложных биологических образцов с минимальной пробоподготовкой. Важно отметить, что в ГКР-спектроскопии используют широкий диапазон частот возбуждения, что позволяет подобрать источник возбуждения с минимальной фоновой аутофлуоресценцией и фоторазрушением образца. Тем не менее применение ГКР-спектроскопии для определения нейромедиаторов на практике на сегодняшний день находится на начальной стадии [9-11, 86]. Недавно показана возможность применения ГКР-спектроскопии для определения досамина в диапазоне концентраций 1-10 мМ [87, 88], описаны методики, позволяющие определять ДА в диапазоне 0,01-0,1 фМ. Селективность определения ДА продемонстрирована в присутствии аскорбиновой кислоты, глюкозы, L-цистеина, тирозина, катехола, фенилэтиламина и сывороточного альбумина [89]. Метод ГКР-спектроскопии легко комбинируется с другими методами, например, селективность электрохимического определения нейромедиаторов в биологических жидкостях ограничивается присутствием таких компонентов, как аскорбиновая кислота, окислительно-восстановительный потенциал которой практически совпадает с потенциалом ДА [90]. При использовании коллоидных растворов серебра удалось понизить нижнюю границу определяемых концентраций до 5 нМ [91], при этом описаны примеры образования комплексов с переносом заряда, которое может способствовать формированию стабильного и интенсивного ГКР-сигнала [92, 93]. Несомненно, рассмотренные подходы открывают новые возможности существенного снижения пределов обнаружения актуальных аналитов до пико- и фемтомолярных концентраций, что является важным шагом вперед на пути использования ГКР для биомедицинской диагностики.

\section{ВЫВОДЫ}

Метод ГКР имеет значительные перспективы для биомедицинского анализа образцов с матрицей сложного многокомпонентного состава, поскольку сочетает одновременно высокие чувствительность и селективность с минимальной пробоподготовкой, а также открывает возможности для мультиплексного определения аналитов в биологических матрицах без предварительной подготовки проб к анализу, в том числе неинвазивно. Для дальнейшего развития метода необходимо развитие материаловедческих аспектов применения ГКР-активных наноструктур в биомедицинских условиях, а также выполнение новых комплексных исследований, направленных на изучение действия наноструктур на исследуемые биологические объекты; оценку изменения свойств наноструктур в 
биологических жидкостях и при контакте с клетками. Весьма перспективна разработка доступных, простых в аппаратурном оснащении и исполнении, экспрессных и в то же время достаточно чувствительных и селективных методик для мультиплексного определения маркеров нейромедиаторного обмена и других биомаркеров для ранней диагностики заболеваний, в том числе на уровне скрининга живых клеток и функциональных клеточных органелл. По мнению авторов, создание мультиплексных оптических систем для определения маркеров заболеваний в биологических жидкостях, а также клеточных структурах является наиболее перспективным направлением совершенствования методов современной клинической диагностики.

\section{Литература}

1. Semkina A, Abakumov M, Grinenko N, Abakumov A, Skorikov A, Mironova $\mathrm{E}$ et al. Core-shell-corona doxorubicin-loaded superparamagnetic $\mathrm{Fe} 3 \mathrm{O} 4$ nanoparticles for cancer theranostics. Colloids Surf B Biointerfaces. 2015; (136): 1073-80.

2. Chekhonin VP, Baklaushev VP, Yusubalieva GM, Belorusova AE, Gulyaev MV, Tsitrin EB et al. Targeted delivery of liposomal nanocontainers to the peritumoral zone of glioma by means of monoclonal antibodies against GFAP and the extracellular loop of Cx43. Nanomedicine. 2012; 8 (1): 63-70.

3. Nukolova NV, Aleksashkin AD, Abakumova TO, Morozova AY, Gubskiy IL, Kirzhanova EA et al. Multilayer polyion complex nanoformulations of superoxide dismutase 1 for acute spinal cord injury. J Control Release. 2018; (270): 226-36.

4. Ковалева Е. В., Синюкова Г. Т., Данзанова Т. Ю., Лепэдату П. И., Гудилина Е. А., Возможности УЗИ с применением контрастного усиления в диагностике метастазов в печени у больных колоректальным раком. Колопроктология. 2018; 1 (63): 36-42.

5. Бердников С. Н., Шолохов В. Н., Синюкова Г. Т., Гудилина Е. А., Абгарян М. Г., Калинин А. Е. и др. Дифференциальная диагностика очаговых гиперэхогенных образований в печени. Колопроктология. 2017; 2 (60): 19-25.

6. Nirmala D. Review: Medical image contrast enhancement techniques, Research Journal of Pharmaceutical Biological and Chemical Sciences. 2015; 6 (3): 321-9.

7. Chen F, Hableel G, Zhao ER, Jokerst JV. Multifunctional nanomedicine with silica: Role of silica in nanoparticles for theranostic, imaging and drug monitoring. J Colloid and Interface Science. 2018; (521): 261-79.

8. Balthazar $\mathrm{P}$, Shinagare $\mathrm{AB}$, Tirumani $\mathrm{SH}$, Jagannathan JP Ramaiya NH, Khorosani R. Gastroenteropancreatic neuroendocrine tumors: impact of consistent contrast agent selection on radiologists' confidence in hepatic lesion assessment on restarding MRls. Abdominal Radiology. 2018; 6 (43): 1386-92.

9. Еремина О. Е., Семенова А. А., Сергеева Е. А., Браже Н. А., Максимов Г. В., Шеховцова Т. Н. и др. Спектроскопия гигантского комбинационного рассеяния в современном химическом анализе: достижения и перспективы использования. Успехи химии. 2018; 87 (8): 741-70.

10. Вацадзе С. З., Еремина О. Е., Веселова И. А., Калмыков С. Н., Ненайденко В. Г., Радиофармпрепараты группы катехоламинов, меченные 18F, в диагностике нейродегенеративных заболеваний и нейроэндокринных опухолей: подходы к синтезу и перспективы развития. Успехи Химии. 2018; 87 (4): 350-73.

11. Веселова И. А., Сергеева Е. А., Македонская М. И., Еремина О. Е., Калмыков С. Н., Шеховцова Т. Н., Методь определения маркеров нейромедиаторного обмена в целях клинической диагностики. Журнал аналитической химии 2016; 71 (12): 1235-49.

12. Kneipp K, Wang Y, Kneipp H, Perelman LT, Itzkan I, Dasari RR et al. Single molecule detection using surface-enhanced Raman scattering (SERS). Phys Rev Lett. 1997; (78): 1667-70.

13. Оленин А. Ю., Лисичкин Г.В.Получение, динамика структуры объема и поверхности металлических наночастиц в конденсированных средах. Успехи химии. 2011; 80: 605-35.

14. Cialla D, März A, Böhme R, Theil F, Weber K, Schmitt M et al. Surface-enhanced Raman spectroscopy (SERS): Progress and trends. Anal Bioanal Chem. 2012; (403): 27-54.

15. Laing S, Gracie K, Faulds K. Multiplex in vitro detection using SERS. Chem Soc Rev. 2016; (45): 1901-18.
16. Semenova AA, Goodilin EA, Brazhe NA, Ivanov VK, Baranchikov AE, Lebedev VA et al. Planar SERS nanostructures with stochastic silver ring morpholgy for biosensor chips. J Mater Chem. 2012; (22): 24530-44.

17. Semenova AA, Brazhe NA, Parshina EY, Sarycheva AS, Maksimov GV, Goodilin EA. A new route for SERS analysis of intact erythrocytes using polydisperse silver nanoplatelets on biocompatible scaffolds. RSC Adv. 2016; (6): 85156-63.

18. Brazhe NA, Evlyukhin AB, Goodilin EA, Semenova AA, Novikov SM, Bozhevolnyi SI et al. Probing cytochrome $\mathrm{c}$ in living mitochondria with surface-enhanced Raman spectroscopy. Sci Rep. 2015; (5): 13793(1)-13793(13)

19. Durmanov NN, Guliev RR, Eremenko AV, Boginskaya IA, Ryzhikov IA, Trifonova EA et al. Non-labeled selective virus detection with novel SERS-active porous silver nanofilms fabricated by Electron Beam Physical Vapor Deposition. Sens Actuators B. 2018; (257): 37-47.

20. Nechaeva N, Prokopkina T, Makhaeva G, Rudakova E, Boltneva N, Dishovsky et al. Quantitative butyrylcholinesterase activity detection by surface-enhanced Raman spectroscopy. Sens Actuators B. 2018; (259): 75-82

21. Kneipp J, Kneipp H, Wittig B, Kneipp K. One- and two-photon excited optical ph probing for cells using surface-enhanced Raman and hyper-Raman nanosensors. Nano Lett. 2007; (7): 2819-23.

22. Drescher D, Kneipp J. Nanomaterials in complex biological systems: insights from Raman spectroscopy. Chem Soc Rev. 2012; (41): 5780-99.

23. Wood BR, Caspers P, Puppels GJ, Pandiancherri S, McNaughton D. Resonance Raman spectroscopy of red blood cells using nearinfrared laser excitation. Anal Bioanal Chem. 2007; (387): 1691703.

24. Brazhe NA, Parshina EY, Khabatova W, Semenova AA, Brazhe AR, Yusipovich Al et al. Tuning SERS for living erythrocytes: Focus on nanoparticle size and plasmon resonance position. J Raman Spectrosc. 2013; (44): 686-94.

25. Semenova AA, Brazhe NA, Parshina EY, Ivanov VK, Maksimov GV, Goodilin EA. Aqueous diaminsilver hydroxide as a precursor of pure silver nanoparticles for SERS probing of living erythrocytes. Plasmonics. 2013; (9): 227-35.

26. Jarvis RM, Goodacre R. Discrimination of bacteria using surfaceenhanced Raman spectroscopy. Anal Chem. 2004; (76): 40-7.

27. Wang P, Pang S, Chen J, McLandsborough L, Nugen SR, Fan M et al. Label-free mapping of single bacterial cells using surfaceenhanced Raman spectroscopy. Analyst. 2016; (141): 1356-62.

28. Granger JH, Schlotter NE, Crawford AC, Porter MD. Prospects for point-of-care pathogen diagnostics using surface-enhanced Raman scattering (SERS). Chem Soc Rev. 2016; (45): 3865-82.

29. Hoang $V$, Tripp RA, Rota P, Dluhy RA. Identification of individual genotypes of measles virus using surface enhanced Raman spectroscopy. Analyst. 2010; (135): 3103-9.

30. Luo S-C, Sivashanmugan K, Liao J-D, Yao C-K, Peng H-C. Nanofabricated SERS-active substrates for single-molecule to virus detection in vitro: A review. Biosens Bioelectron. 2014; (61): 232-40.

31. El-Said WA, Kim SU, Choi J-W. Monitoring in vitro neural stem cell differentiation based on surface-enhanced Raman spectroscopy using a gold nanostar array. J Mater Chem C. 2015; (3): 3848-59.

32. Han J, Qian X, Wu Q, Jha R, Duan J, Yang Z et al. Novel surface- 
enhanced Raman scattering-based assays for ultra-sensitive detection of human pluripotent stem cells. Biomaterials. 2016; (105): 66-76.

33. Howes PD, Rana S, Stevens MM. Plasmonic nanomaterials for biodiagnostics. Chem Soc Rev. 2014; (43): 383-8.

34. McAughtrie S, Faulds K, Graham D. Surface enhanced Raman spectroscopy (SERS): potential applications for disease detection and treatment. J Photochem Photobiol C. 2014; (21): 40-53.

35. Puppels GJ, de Mul FFM, Otto C, Greve J, Robert-Nicoud M, Arndt-Jovin DJ et al. Studying single living cells and chromosomes by confocal Raman microspectroscopy. Nature. 1990; (347): 301-3.

36. Alvarez-Puebla RA, Liz-Marzán LM. SERS-based diagnosis and biodetection. Small. 2010; (6): 604-10.

37. März A, Mönch B, Rösch P, Kiehntopf M, Henkel T, Popp J. Detection of thiopurine methyltransferase activity in lysed red blood cells by means of lab-on-a-chip surface enhanced Raman spectroscopy (LOC-SERS). Anal Bioanal Chem. 2011; (400): 2755-61.

38. Jahn IJ, Žukovskaja O, Zheng X-S, Weber K, Bocklitz TW, Cialla-May $D$ et al. Surface-enhanced Raman spectroscopy and microfluidic platforms: challenges, solutions and potential applications. Analyst. 2017; (142): 1022-47.

39. Kumar S, Goel P, Singh JP. A facile method for fabrication of buckled PDMS silver nanorod arrays as active 3D SERS cages for bacterial sensing. Sens Actuators B. 2017; (241): 577-83.

40. Polavarapu L, Perez-Juste J, Xu Q, Liz-Marzán LM. Optical sensing of biological, chemical and ionic species through aggregation of plasmonic nanoparticles. J Mater Chem C. 2014; (2): $7460-76$.

41. Dhillon A, Nair M, Kumar D. Analytical methods for sensing of health-hazardous arsenic from biotic and abiotic natural resources. Anal Methods. 2015; (7): 10088-108.

42. Xiao L, Zhang M, Liu Z, Bian W, Zhang X, Zhan J. Hydrophobic silver nanowire membrane for swabbing extraction and in situ SERS detection of polycyclic aromatic hydrocarbons on toys. Anal Methods. 2017; (9): 1816-24.

43. Fleischmann M, Hendra PJ, McQuillan AJ. Raman spectra of pyridine adsorbed at a silver electrode. Chem Phys Lett. 1974; (26): $163-6$

44. Wachsmann-Hogiu S, Weeks T, Huser T. Chemical analysis in vivo and in vitro by Raman spectroscopy - From single cells to humans. Curr Opin Biotechnol. 2009; (20): 63-73.

45. Yazdi SH, White IM. A nanoporous optofluidic microsystem for highly sensitive and repeatable surface enhanced Raman spectroscopy detection. Biomicrofluidics. 2012; (6): 14105-59.

46. Sharma VK, Yngard RA, Lin Y. Green synthesis and their antimicrobial activities. Adv Colloid Interface Sci. 2009; (145): 83-96.

47. Sun Y. Shape-controlled synthesis of gold and silver nanoparticles. Science. 2002; (298): 2176-9.

48. Guerrero-Martínez A, Barbosa S, Pastoriza-Santos I, Liz-Marzán LM. Nanostars shine bright for you: colloidal synthesis, properties and applications of branched metallic nanoparticles. Curr Opin Colloid Interface Sci. 2011; (16): 118-27.

49. Lim B, Xia Y. Metal nanocrystals with highly branched morphologies. Angew Chem Int Ed. 2011; (50): 76-85.

50. Pietrobon B, Kitaev V. Photochemical synthesis of monodisperse size-controlled silver decahedral nanoparticles and their remarkable optical properties. Chem Mater. 2008; (20): 5186-90.

51. Phan-Quang GC, Lee HK, Phang IY, Ling XY. Plasmonic colloidosomes as three-dimensional SERS platforms with enhanced surface area for multiphase sub-microliter toxin sensing. Angew Chem Int Ed. 2015; (54): 9691-5.

52. Tien D-C, Liao C-Y, Huang J-C, Tseng K-H, Lung J-K, Tsung T-T et al. Novel technique for preparing a nano-silver water suspension by the arc-discharge method. Rev Adv Mater Sci. 2008; (18): 750-6.

53. Gongalsky MB, Osminkina LA, Pereira A, Manankov AA, Fedorenko AA, Vasiliev AN et al. Laser-synthesized oxidepassivated bright Si quantum dots for bioimaging. Sci Rep. 2016; (6): 24732(1)-24732(8)

54. Nadagouda MN, Varma RS. Green synthesis of silver and palladium nanoparticles at room temperature using coffee and tea extract. Green Chem. 2008; (10): 859-62.

55. Moulton MC, Braydich-Stolle LK, Nadagouda MN, Kunzelman S, Hussain SM, Varma RS. Synthesis, characterization and biocompatibility of "green" synthesized silver nanoparticles using tea polyphenols. Nanoscale. 2010; (2): 763-70.

56. Hwang $\mathrm{H}$, Chon $\mathrm{H}$, Choo J, Park JK. Optoelectrofluidic sandwich immunoassays for detection of human tumor marker using surface-enhanced Raman scattering. Analyt Chem. 2010; (82): 7603-10.

57. Li J-M, Ma W-F, Wei C, Guo J, Hu J, Wang C-C. Poly(styreneco-acrylic acid) core and silver nanoparticle/silica shell composite microspheres as high performance surface-enhanced Raman spectroscopy (SERS) substrate and molecular barcode label. $J$ Mater Chem. 2011; (21): 5992-98.

58. Chen J-W, Lei Y, Liu X-J, Jiang J-H, Shen G-L, Yu R-Q. Immunoassay using surface-enhanced Raman scattering based on aggregation of reporter-labeled immunogold nanoparticles. Anal Bioanal Chem. 2008; (392): 187-93.

59. Ma K, Yuen JM, Shah NC, Walsh JT, Glucksberg MR, Van Duyne RP. In Vivo, transcutaneous glucose sensing using surface-enhanced spatially offset Raman spectroscopy: multiple rats, improved hypoglycemic accuracy, low incident power, and continuous monitoring for greater than 17 days. Anal Chem. 2011; (83): 9146-52.

60. Pînzaru SC, Andronie LM, Domsa I, Cozar O, Astilean S. Bridging biomolecules with nanoparticles: surface-enhanced Raman scattering from colon carcinoma and normal tissue. J Raman Spectrosc. 2008; (39): 331-4.

61. Wang X, Qian X, Beitler JJ, Chen ZG, Khuri FR, Lewis MM et al. Detection of circulating tumor cells in human peripheral blood using surface-enhanced Raman scattering nanoparticles. Cancer Res. 2011; (71): 1526-32.

62. Thomson PIT, Camus VL, Hu Y, Campbell CJ. Series of quinonecontaining nanosensors for biologically relevant redox potential determination by surface-enhanced Raman spectroscopy. Anal Chem. 2015; 87 (9): 4719-35.

63. Qu L-L, Li D-W, Qin L-X, Mu J, Fossey JS, Long Y-T. Selective and sensitive detection of intracellular O2(•-) using Au NPs/ cytochrome c as SERS nanosensors. Anal Chem. 2013; 85 (20): 9549-55.

64. Sivanesan A, Witkowska E, Adamkiewicz W, Dziewit $€$, Kamińska A, Waluk J. Nanostructured silver-gold bimetallic SERS substrates for selective identification of bacteria in human blood. Analyst. 2013; 139 (5): 1037-43.

65. Vitol EA, Orynbayeva Z, Bouchard MJ, Azizkhan-Clifford J, Friedman G, Gogotsi Y. In situ intracellular spectroscopy with surface enhanced Raman spectroscopy (SERS)-enabled nanopipettes. ACS Nano. 2009; 3 (11): 3529-36.

66. Vitol EA, Brailoiu E, Orynbayeva Z, Dun NJ, Friedman G, Gogotsi Y. Surface-enhanced Raman spectroscopy as a tool for detecting Ca2+ mobilizing second messengers in cell extracts. Anal Chem. 2010; 8 (16): 6770-4.

67. Zhang Q, Lu X, Tang P, Zhang D, Tian J, Zhong L. Gold nanoparticle (AuNP)-based surface-enhanced Raman scattering (SERS) probe of leukemic lymphocytes. Plasmonics. 2016; (11): $1361-8$.

68. Berezhna S, Wohlrab H, Champion PM. Resonance Raman investigations of cytochrome c conformational change upon interaction with the membranes of intact and $\mathrm{Ca} 2+-$ exposed mitochondria. Biochemistry. 2003; (42): 6149-58.

69. Pankratova MS, Baizhumanov AA, Yusipovich Al, Faassen M, Shiryaeva TYu, Peterkova VA et al. Imbalance in the blood antioxidant systemin growth hormone-deficient children before and after 1 year of recombinant growth hormone therapy. Peer J. 2015; (3): e1055(1)-e1055(12).

70. Brazhe NA, Baizhumanov AA, Parshina EYu, Yusipovich Al, Akhalaya MYa, Yarlykova YuV et al. Studies of the blood antioxidant system and oxygen-transporting properties of human erythrocytes during 105-day isolation. Human physiology. 2014; (40): 804-9.

71. Rodan LH, Gibson KM, Pearl PL. Clinical Use of CSF Neurotransmitters J Pediatr Neurol. 2015; 53 (4): 277-86. 
72. Eisenhofer G, Kopin IJ, Goldstein DS. Catecholamine metabolism: a contemporary view with implications for physiology and medicine. Pharmacol Rev. 2004; 56 (3): 331-49.

73. Goldstein DS, Kopin IJ, Sharabi Y. Catecholamine autotoxicity. Implications for pharmacology and therapeutics of Parkinson disease and related disorders. Pharmacol Ther. 2014; 144 (3): 268-82.

74. Postuma RB, Gagnon JF, Vendette M, Montplaisir JY. Markers of neurodegeneration in idiopathic rapid eye movement sleep behaviour disorder and Parkinson's disease. Brain. 2009; 132 (12): 3298-307.

75. Subramaniam R. Pheochromocytoma - current concepts in diagnosis and management. Trends Anaesth Crit Care. 2011; 1 (2): 104-10.

76. Yangong H, Shi C, Shahbaz M, Zhengchuan N, Wang J, Liang B et al. Diagnosis and treatment experience of rectal carcinoid (a report of 312 cases). Int J Surg. 2014; 12 (5): 408-11.

77. Sadilkova K, Dugaw K, Benjamin D, Jack RM. Analysis of vanillylmandelic acid and homovanillic acid by UPLC-MS/MS in serum for diagnostic testing for neuroblastoma. Clin Chim Acta. 2013; (424): 253-7.

78. Rodriguez MC, Rubianes MD, Rivas GA. Highly selective determination of dopamine in the presence of ascorbic acid and serotonin at glassy carbon electrodes modified with carbon nanotubes dispersed in polyethylenimine. J Nanosci Nanotechnol. 2008; 8 (11): 6003-9.

79. Mazloum-Ardakani M, Khoshroo A. High performance electrochemical sensor based on fullerene-functionalized carbon nanotubes/ionic liquid: Determination of some catecholamines. Electrochem Comm. 2014; (42): 9-12

80. Rezaei B, Boroujeni MK, Ensafi AA. Fabrication of DNA, o-phenylenediamine, and gold nanoparticle bioimprinted polymer electrochemical sensor for the determination of dopamine. Biosens Bioelectron. 2015; (66): 490-6.

81. Gao N, Xu Z, Wang F, Dong SJ. Sensitive biomimetic sensor based on molecular imprinting at functionalized indium tin oxide electrodes. Electroanalisis. 2007; (19): 1655-60.

82. Poliakov AE, Dumshakova AV, Muginova SV, Shekhovtsova TN. A peroxidase-based method for the determination of dopamine, adrenaline, and $\alpha$-methyldopa in the presence of thyroid hormones in pharmaceutical forms. Talanta. 2011; 84 (3): 710-6.

83. Huang H, Gao Y, Shi F, Wang G, Shah SM, Su X. Determination of catecholamine in human serum by a fluorescent quenching method based on a water-soluble fluorescent conjugated polymer-enzyme hybrid system. Analyst. 2012; 137 (6): 1481-6.

84. Liu CH, Yu CJ, Tseng WL. Fluorescence assay of catecholamines based on the inhibition of peroxidase-like activity of magnetite nanoparticles. Anal Chim Acta. 2012; (745): 143-8.

85. Schulze HG, Blades MW, Bree AV, Gorzalka BB, Greek LS, Turner RFB. Characteristics of backpropagation neural networks employed in the identification of neurotransmitter Raman spectra. Appl Spectrosc. 1994; (48): 50-7.

86. Sharma B, Frontiera RR, Henry Al, Ringe E, Van Duyne RP. SERS: Materials, applications, and the future. Mater Today. 2012; (15): 16-25.

87. Lim JW, Kang IJ. Fabrication of chitosan-gold nanocomposites combined with optical fiber as SERS substrates to detect dopamine molecules. Bull Korean Chem Soc. 2014; (35): 25-9.

88. Lim JW, Kang IJ. Chitosan-gold nano composite for dopamine analysis using Raman scattering. Bull Korean Chem Soc. 2013; (34): 237-42.

89. Tang L, Li S, Han F, Liu L, Xu L, Ma W et al. SERS-active Au@Ag nanorod dimers for ultrasensitive dopamine detection. Biosens Bioelectron. 2015; (71): 7-12.

90. Lee NS, Hsieh YZ, Paisley RF, Morris MD. Surface enhanced Raman spectroscopy of the catecholamine neurotransmitters and related compounds. Anal Chem. 1998; (60): 442-6.

91. Kneipp K, Wang Y, Dasari RR, Feld MS. Near-infrared surfaceenhanced Raman scattering (NIR-SERS) of neurotransmitters in colloidal silver solutions. Spectrochim Acta. 1995; (51A): 481-7.

92. Volkan M, Stokes DL, Vo-Dinh T. Surface-Enhanced Raman of dopamine and neurotransmitters using sol-gel substrates and polymer-coated fiber-optic probes. Appl Spectrosc. 2000; 54 (12): 1842-8.

93. Barreto WJ, Barreto SRG, Ando RA, Santos PS, DiMauro E, Jorge T. Raman, IR, UV-vis and EPR characterization of two copper dioxolene complexes derived from L-DOPA and dopamine. Spectrochim. Acta Part A. 2008; 71 (4): 1419-24.

\section{References}

1. Semkina A, Abakumov M, Grinenko N, Abakumov A, Skorikov A, Mironova $E$ et al. Core-shell-corona doxorubicin-loaded superparamagnetic $\mathrm{Fe} 3 \mathrm{O} 4$ nanoparticles for cancer theranostics. Colloids Surf B Biointerfaces. 2015; (136): 1073-80.

2. Chekhonin VP, Baklaushev VP, Yusubalieva GM, Belorusova AE, Gulyaev MV, Tsitrin EB et al. Targeted delivery of liposomal nanocontainers to the peritumoral zone of glioma by means of monoclonal antibodies against GFAP and the extracellular loop of Cx43 Nanomedicine. 2012; 8 (1): 63-70.

3. Nukolova NV, Aleksashkin AD, Abakumova TO, Morozova AY, Gubskiy IL, Kirzhanova EA et al. Multilayer polyion complex nanoformulations of superoxide dismutase 1 for acute spinal cord injury. J Control Release. 2018; (270): 226-36.

4. Kovaleva EV, Sinyukova GT, Danzanova TY, Lepedatu PI, Gidulina EA Vozmozhnosti UZI s primeneniyem contrastnogo usileniya $v$ diagnostike metastazov $\mathrm{v}$ pecheni $\mathrm{u}$ bolnih kolorectalnim rakom. Koloproktologiya. 2018; 1 (63): 36-42.

5. Bednikov SN, Sholokhov VN, Sinyukova GT, Goodilina EA Abgaryan MG, Kalinin AE i dr. Differentsialnaya diagnostika ochagovih giperekhogennih orazovaniy v pecheni. Koloproktologiya. 2017; 2 (60): 19-25.

6. Nirmala D. Review: Medical image contrast enhancement techniques, Research Journal of Pharmaceutical Biological and Chemical Sciences. 2015; 6 (3): 321-9.

7. Chen F, Hableel G, Zhao ER, Jokerst JV. Multifunctional nanomedicine with silica: Role of silica in nanoparticles for theranostic, imaging and drug monitoring. J Colloid and Interface Science. 2018; (521): 261-79.

8. Balthazar $P$, Shinagare $A B$, Tirumani $S H$, Jagannathan JP, Ramaiya NH, Khorosani R. Gastroenteropancreatic neuroendocrine tumors: impact of consistent contrast agent selection on radiologists' confidence in hepatic lesion assessment on restarding MRls. Abdominal Radiology. 2018; 6 (43): 1386-92.

9. Eremina OE, Semenova AA, Sergeeva EA, Brazhe NA, Maksimov GV, Shekhovtsova TN, Goodilin EA, Veselova IA, Surface enhanced Raman spectroscopy in modern chemical analysis: achievements and prospects. Russ Chem Rev. 2018; 87 (8): 741-70, DOI: doi. org/10.1070/RCR4804.

10. Vatsadze SZ, Eremina OE, Veselova IA, Kalmykov SN, Nenajdenko VG $18 \mathrm{~F}$-Labelled catecholamine type radiopharmaceuticals in the diagnosis of neurodegenerative diseases and neuroendocrine tumours: approaches to synthesis and development prospects. Russ Chem Rev. 2018; 87 (4): 350-73, DOI: doi.org/10.1070/ RCR4752/

11. Veselova IA, Sergeeva EA, Makedonskaya MI, Eremina OE, Kalmykov SN, Shekhovtsova TN. Metodi opredeleniya markerov neyromediatornogo obmena $\vee$ celyah klinicheskoy diagnostiki. Russian Journal of Analytical chemistry. 2016; 71 (12): 1235-49.

12. Kneipp K, Wang Y, Kneipp H, Perelman LT, Itzkan I, Dasari RR et al. Single molecule detection using surface-enhanced Raman scattering (SERS). Phys Rev Lett. 1997; (78): 1667-70.

13. Olenin AY, Lisichkin GV. Metal nanoparticles in condensed media: preparation and the bulk and surface structural dynamics. Russ Chem Rev. 2011; (80): 605-35.

14. Cialla D, März A, Böhme R, Theil F, Weber K, Schmitt M et al. Surface-enhanced Raman spectroscopy (SERS): Progress and 
trends. Anal Bioanal Chem. 2012; (403): 27-54.

15. Laing S, Gracie K, Faulds K. Multiplex in vitro detection using SERS. Chem Soc Rev. 2016; (45): 1901-18.

16. Semenova AA, Goodilin EA, Brazhe NA, Ivanov VK, Baranchikov AE, Lebedev VA et al. Planar SERS nanostructures with stochastic silver ring morpholgy for biosensor chips. J Mater Chem. 2012; (22): 24530-44.

17. Semenova AA, Brazhe NA, Parshina EY, Sarycheva AS, Maksimov GV, Goodilin EA. A new route for SERS analysis of intact erythrocytes using polydisperse silver nanoplatelets on biocompatible scaffolds. RSC Adv. 2016; (6): 85156-63.

18. Brazhe NA, Evlyukhin AB, Goodilin EA, Semenova AA, Novikov SM, Bozhevolnyi SI et al. Probing cytochrome $\mathrm{C}$ in living mitochondria with surface-enhanced Raman spectroscopy. Sci Rep. 2015; (5): 13793(1)-13793(13).

19. Durmanov NN, Guliev RR, Eremenko AV, Boginskaya IA, Ryzhikov IA, Trifonova EA et al. Non-labeled selective virus detection with novel SERS-active porous silver nanofilms fabricated by Electron Beam Physical Vapor Deposition. Sens Actuators B. 2018; (257): 37-47.

20. Nechaeva N, Prokopkina T, Makhaeva G, Rudakova E, Boltneva N, Dishovsky et al. Quantitative butyrylcholinesterase activity detection by surface-enhanced Raman spectroscopy. Sens Actuators B. 2018; (259): 75-82.

21. Kneipp J, Kneipp H, Wittig B, Kneipp K. One- and two-photon excited optical ph probing for cells using surface-enhanced Raman and hyper-Raman nanosensors. Nano Lett. 2007; (7): 2819-23.

22. Drescher D, Kneipp J. Nanomaterials in complex biological systems: insights from Raman spectroscopy. Chem Soc Rev. 2012; (41): 5780-99.

23. Wood BR, Caspers P, Puppels GJ, Pandiancherri S, McNaughton D. Resonance Raman spectroscopy of red blood cells using nearinfrared laser excitation. Anal Bioanal Chem. 2007; (387): 1691-703.

24. Brazhe NA, Parshina EY, Khabatova W, Semenova AA, Brazhe AR, Yusipovich Al et al. Tuning SERS for living erythrocytes: Focus on nanoparticle size and plasmon resonance position. J Raman Spectrosc. 2013; (44): 686-94.

25. Semenova AA, Brazhe NA, Parshina EY, Ivanov VK, Maksimov GV, Goodilin EA. Aqueous diaminsilver hydroxide as a precursor of pure silver nanoparticles for SERS probing of living erythrocytes. Plasmonics. 2013; (9): 227-35.

26. Jarvis RM, Goodacre R. Discrimination of bacteria using surfaceenhanced Raman spectroscopy. Anal Chem. 2004; (76): 40-7.

27. Wang P, Pang S, Chen J, McLandsborough L, Nugen SR, Fan M et al. Label-free mapping of single bacterial cells using surfaceenhanced Raman spectroscopy. Analyst. 2016; (141): 1356-62.

28. Granger JH, Schlotter NE, Crawford AC, Porter MD. Prospects for point-of-care pathogen diagnostics using surface-enhanced Raman scattering (SERS). Chem Soc Rev. 2016; (45): 3865-82.

29. Hoang V, Tripp RA, Rota P, Dluhy RA. Identification of individual genotypes of measles virus using surface enhanced Raman spectroscopy. Analyst. 2010; (135): 3103-9.

30. Luo S-C, Sivashanmugan K, Liao J-D, Yao C-K, Peng H-C. Nanofabricated SERS-active substrates for single-molecule to virus detection in vitro: A review. Biosens Bioelectron. 2014; (61): 232-40.

31. El-Said WA, Kim SU, Choi J-W. Monitoring in vitro neural stem cell differentiation based on surface-enhanced Raman spectroscopy using a gold nanostar array. J Mater Chem C. 2015; (3): 3848-59.

32. Han J, Qian X, Wu Q, Jha R, Duan J, Yang Z et al. Novel surfaceenhanced Raman scattering-based assays for ultra-sensitive detection of human pluripotent stem cells. Biomaterials. 2016; (105): 66-76.

33. Howes PD, Rana S, Stevens MM. Plasmonic nanomaterials for biodiagnostics. Chem Soc Rev. 2014; (43): 383-8.

34. McAughtrie S, Faulds K, Graham D. Surface enhanced Raman spectroscopy (SERS): potential applications for disease detection and treatment. J Photochem Photobiol C. 2014; (21): 40-53.

35. Puppels GJ, de Mul FFM, Otto C, Greve J, Robert-Nicoud M, Arndt-Jovin DJ et al. Studying single living cells and chromosomes by confocal Raman microspectroscopy. Nature. 1990; (347): 301-3.
36. Alvarez-Puebla RA, Liz-Marzán LM. SERS-based diagnosis and biodetection. Small. 2010; (6): 604-10.

37. März A, Mönch B, Rösch P, Kiehntopf M, Henkel T, Popp J. Detection of thiopurine methyltransferase activity in lysed red blood cells by means of lab-on-a-chip surface enhanced Raman spectroscopy (LOC-SERS). Anal Bioanal Chem. 2011; (400): 2755-61.

38. Jahn IJ, Žukovskaja O, Zheng X-S, Weber K, Bocklitz TW, Cialla-May $D$ et al. Surface-enhanced Raman spectroscopy and microfluidic platforms: challenges, solutions and potential applications. Analyst. 2017; (142): 1022-47.

39. Kumar S, Goel P, Singh JP. A facile method for fabrication of buckled PDMS silver nanorod arrays as active 3D SERS cages for bacterial sensing. Sens Actuators B. 2017; (241): 577-83.

40. Polavarapu L, Perez-Juste J, Xu Q, Liz-Marzán LM. Optical sensing of biological, chemical and ionic species through aggregation of plasmonic nanoparticles. J Mater Chem C. 2014; (2): 7460-76

41. Dhillon A, Nair M, Kumar D. Analytical methods for sensing of health-hazardous arsenic from biotic and abiotic natural resources. Anal Methods. 2015; (7): 10088-108.

42. Xiao L, Zhang M, Liu Z, Bian W, Zhang X, Zhan J. Hydrophobic silver nanowire membrane for swabbing extraction and in situ SERS detection of polycyclic aromatic hydrocarbons on toys. Anal Methods. 2017; (9): 1816-24.

43. Fleischmann M, Hendra PJ, McQuillan AJ. Raman spectra of pyridine adsorbed at a silver electrode. Chem Phys Lett. 1974; (26): 163-6.

44. Wachsmann-Hogiu S, Weeks T, Huser T. Chemical analysis in vivo and in vitro by Raman spectroscopy - From single cells to humans. Curr Opin Biotechnol. 2009; (20): 63-73.

45. Yazdi SH, White IM. A nanoporous optofluidic microsystem for highly sensitive and repeatable surface enhanced Raman spectroscopy detection. Biomicrofluidics. 2012; (6): 14105-59.

46. Sharma VK, Yngard RA, Lin Y. Green synthesis and their antimicrobial activities. Adv Colloid Interface Sci. 2009; (145): 83-96.

47. Sun Y. Shape-controlled synthesis of gold and silver nanoparticles. Science. 2002; (298): 2176-9.

48. Guerrero-Martínez A, Barbosa S, Pastoriza-Santos I, Liz-Marzán LM. Nanostars shine bright for you: colloidal synthesis, properties and applications of branched metallic nanoparticles. Curr Opin Colloid Interface Sci. 2011; (16): 118-27.

49. Lim B, Xia Y. Metal nanocrystals with highly branched morphologies. Angew Chem Int Ed. 2011; (50): 76-85.

50. Pietrobon B, Kitaev V. Photochemical synthesis of monodisperse size-controlled silver decahedral nanoparticles and their remarkable optical properties. Chem Mater. 2008; (20): 5186-90.

51. Phan-Quang GC, Lee HK, Phang IY, Ling XY. Plasmonic colloidosomes as three-dimensional SERS platforms with enhanced surface area for multiphase sub-microliter toxin sensing. Angew Chem Int Ed. 2015; (54): 9691-5.

52. Tien D-C, Liao C-Y, Huang J-C, Tseng K-H, Lung J-K, Tsung T-T et al. Novel technique for preparing a nano-silver water suspension by the arc-discharge method. Rev Adv Mater Sci. 2008; (18): 750-6.

53. Gongalsky MB, Osminkina LA, Pereira A, Manankov AA, Fedorenko AA, Vasiliev AN et al. Laser-synthesized oxidepassivated bright Si quantum dots for bioimaging. Sci Rep. 2016; (6): 24732(1)-24732(8).

54. Nadagouda MN, Varma RS. Green synthesis of silver and palladium nanoparticles at room temperature using coffee and tea extract. Green Chem. 2008; (10): 859-62.

55. Moulton MC, Braydich-Stolle LK, Nadagouda MN, Kunzelman S, Hussain SM, Varma RS. Synthesis, characterization and biocompatibility of "green" synthesized silver nanoparticles using tea polyphenols. Nanoscale. 2010; (2): 763-70.

56. Hwang H, Chon H, Choo J, Park JK. Optoelectrofluidic sandwich immunoassays for detection of human tumor marker using surface-enhanced Raman scattering. Analyt Chem. 2010; (82): 7603-10.

57. Li J-M, Ma W-F, Wei C, Guo J, Hu J, Wang C-C. Poly(styreneco-acrylic acid) core and silver nanoparticle/silica shell composite 
microspheres as high performance surface-enhanced Raman spectroscopy (SERS) substrate and molecular barcode label. J Mater Chem. 2011; (21): 5992-98.

58. Chen J-W, Lei Y, Liu X-J, Jiang J-H, Shen G-L, Yu R-Q. Immunoassay using surface-enhanced Raman scattering based on aggregation of reporter-labeled immunogold nanoparticles. Anal Bioanal Chem. 2008; (392): 187-93.

59. Ma K, Yuen JM, Shah NC, Walsh JT, Glucksberg MR, Van Duyne RP. In Vivo, transcutaneous glucose sensing using surface-enhanced spatially offset Raman spectroscopy: multiple rats, improved hypoglycemic accuracy, low incident power, and continuous monitoring for greater than 17 days. Anal Chem. 2011; (83): 9146-52.

60. Pînzaru SC, Andronie LM, Domsa I, Cozar O, Astilean S. Bridging biomolecules with nanoparticles: surface-enhanced Raman scattering from colon carcinoma and normal tissue. J Raman Spectrosc. 2008; (39): 331-4.

61. Wang X, Qian X, Beitler JJ, Chen ZG, Khuri FR, Lewis MM et al. Detection of circulating tumor cells in human peripheral blood using surface-enhanced Raman scattering nanoparticles. Cancer Res. 2011; (71): 1526-32.

62. Thomson PIT, Camus VL, Hu Y, Campbell CJ. Series of quinonecontaining nanosensors for biologically relevant redox potential determination by surface-enhanced Raman spectroscopy. Anal Chem. 2015; 87 (9): 4719-35.

63. Qu L-L, Li D-W, Qin L-X, Mu J, Fossey JS, Long Y-T. Selective and sensitive detection of intracellular O2(•-) using Au NPS/ cytochrome c as SERS nanosensors. Anal Chem. 2013; 85 (20): 9549-55.

64. Sivanesan A, Witkowska E, Adamkiewicz W, Dziewit Ł, Kamińska A Waluk J. Nanostructured silver-gold bimetallic SERS substrates for selective identification of bacteria in human blood. Analyst. 2013; 139 (5): 1037-43

65. Vitol EA, Orynbayeva Z, Bouchard MJ, Azizkhan-Clifford J, Friedman G, Gogotsi Y. In situ intracellular spectroscopy with surface enhanced Raman spectroscopy (SERS)-enabled nanopipettes. ACS Nano. 2009; 3 (11): 3529-36.

66. Vitol EA, Brailoiu E, Orynbayeva Z, Dun NJ, Friedman G, Gogotsi Y. Surface-enhanced Raman spectroscopy as a tool for detecting $\mathrm{Ca} 2+$ mobilizing second messengers in cell extracts. Anal Chem. 2010; 8 (16): 6770-4.

67. Zhang Q, Lu X, Tang P, Zhang D, Tian J, Zhong L. Gold nanoparticle (AuNP)-based surface-enhanced Raman scattering (SERS) probe of leukemic lymphocytes. Plasmonics. 2016; (11): 1361-8.

68. Berezhna S, Wohlrab H, Champion PM. Resonance Raman investigations of cytochrome c conformational change upon interaction with the membranes of intact and Ca2+-exposed mitochondria. Biochemistry. 2003; (42): 6149-58.

69. Pankratova MS, Baizhumanov AA, Yusipovich Al, Faassen M Shiryaeva TYu, Peterkova VA et al. Imbalance in the blood antioxidant systemin growth hormone-deficient children before and after 1 year of recombinant growth hormone therapy. Peer $\mathrm{J}$. 2015; (3): e1055(1)-e1055(12)

70. Brazhe NA, Baizhumanov AA, Parshina EYu, Yusipovich Al, Akhalaya MYa, Yarlykova YuV et al. Studies of the blood antioxidant system and oxygen-transporting properties of human erythrocytes during 105-day isolation. Human physiology. 2014; (40): 804-9.

71. Rodan LH, Gibson KM, Pearl PL. Clinical Use of CSF Neurotransmitters J Pediatr Neurol. 2015; 53 (4): 277-86.

72. Eisenhofer G, Kopin IJ, Goldstein DS. Catecholamine metabolism: a contemporary view with implications for physiology and medicine. Pharmacol Rev. 2004; 56 (3): 331-49.

73. Goldstein DS, Kopin IJ, Sharabi Y. Catecholamine autotoxicity. Implications for pharmacology and therapeutics of Parkinson disease and related disorders. Pharmacol Ther. 2014; 144 (3): 268-82.

74. Postuma RB, Gagnon JF, Vendette M, Montplaisir JY. Markers of neurodegeneration in idiopathic rapid eye movement sleep behaviour disorder and Parkinson's disease. Brain. 2009; 132 (12): 3298-307

75. Subramaniam R. Pheochromocytoma - current concepts in diagnosis and management. Trends Anaesth Crit Care. 2011; 1 (2): 104-10.

76. Yangong $\mathrm{H}$, Shi $\mathrm{C}$, Shahbaz M, Zhengchuan N, Wang J, Liang B et al. Diagnosis and treatment experience of rectal carcinoid (a report of 312 cases). Int J Surg. 2014; 12 (5): 408-11.

77. Sadilkova K, Dugaw K, Benjamin D, Jack RM. Analysis of vanillyImandelic acid and homovanillic acid by UPLC-MS/MS in serum for diagnostic testing for neuroblastoma. Clin Chim Acta. 2013; (424): 253-7.

78. Rodriguez MC, Rubianes MD, Rivas GA. Highly selective determination of dopamine in the presence of ascorbic acid and serotonin at glassy carbon electrodes modified with carbon nanotubes dispersed in polyethylenimine. J Nanosci Nanotechnol. 2008; 8 (11): 6003-9.

79. Mazloum-Ardakani M, Khoshroo A. High performance electrochemical sensor based on fullerene-functionalized carbon nanotubes/ionic liquid: Determination of some catecholamines. Electrochem Comm. 2014; (42): 9-12.

80. Rezaei B, Boroujeni MK, Ensafi AA. Fabrication of DNA, o-phenylenediamine, and gold nanoparticle bioimprinted polymer electrochemical sensor for the determination of dopamine. Biosens. Bioelectron. 2015; (66): 490-6.

81. Gao N, Xu Z, Wang F, Dong SJ. Sensitive biomimetic sensor based on molecular imprinting at functionalized indium tin oxide electrodes. Electroanalisis. 2007; (19): 1655-60.

82. Poliakov AE, Dumshakova AV, Muginova SV, Shekhovtsova TN. A peroxidase-based method for the determination of dopamine, adrenaline, and $\alpha$-methyldopa in the presence of thyroid hormones in pharmaceutical forms. Talanta. 2011; 84 (3): 710-6.

83. Huang H, Gao Y, Shi F, Wang G, Shah SM, Su X. Determination of catecholamine in human serum by a fluorescent quenching method based on a water-soluble fluorescent conjugated polymer-enzyme hybrid system. Analyst. 2012; 137 (6): 1481-6.

84. Liu CH, Yu CJ, Tseng WL. Fluorescence assay of catecholamines based on the inhibition of peroxidase-like activity of magnetite nanoparticles. Anal Chim Acta. 2012; (745): 143-8.

85. Schulze HG, Blades MW, Bree AV, Gorzalka BB, Greek LS, Turner RFB. Characteristics of backpropagation neural networks employed in the identification of neurotransmitter Raman spectra. Appl Spectrosc. 1994; (48): 50-7.

86. Sharma B, Frontiera RR, Henry Al, Ringe E, Van Duyne RP. SERS: Materials, applications, and the future. Mater Today. 2012; (15): 16-25.

87. Lim JW, Kang IJ. Fabrication of chitosan-gold nanocomposites combined with optical fiber as SERS substrates to detect dopamine molecules. Bull Korean Chem Soc. 2014; (35): 25-9.

88. Lim JW, Kang IJ. Chitosan-gold nano composite for dopamine analysis using Raman scattering. Bull Korean Chem Soc. 2013; (34): 237-42.

89. Tang L, Li S, Han F, Liu L, Xu L, Ma W et al. SERS-active Au@Ag nanorod dimers for ultrasensitive dopamine detection. Biosens Bioelectron. 2015; (71): 7-12.

90. Lee NS, Hsieh YZ, Paisley RF, Morris MD. Surface enhanced Raman spectroscopy of the catecholamine neurotransmitters and related compounds. Anal Chem. 1998; (60): 442-6.

91. Kneipp K, Wang Y, Dasari RR, Feld MS. Near-infrared surfaceenhanced Raman scattering (NIR-SERS) of neurotransmitters in colloidal silver solutions. Spectrochim Acta. 1995; (51A): 481-7.

92. Volkan M, Stokes DL, Vo-Dinh T. Surface-Enhanced Raman of dopamine and neurotransmitters using sol-gel substrates and polymer-coated fiber-optic probes. Appl Spectrosc. 2000; 54 (12): 1842-8.

93. Barreto WJ, Barreto SRG, Ando RA, Santos PS, DiMauro E, Jorge T. Raman, IR, UV-vis and EPR characterization of two copper dioxolene complexes derived from L-DOPA and dopamine. Spectrochim. Acta Part A. 2008; 71 (4): 1419-24. 